\title{
Nils Grosche
}

\section{Rechtsfortbildung im Unionsrecht}

Eine Untersuchung zum Phänomen richterlicher Rechtsfortbildung durch den Gerichtshof der Europäischen Union

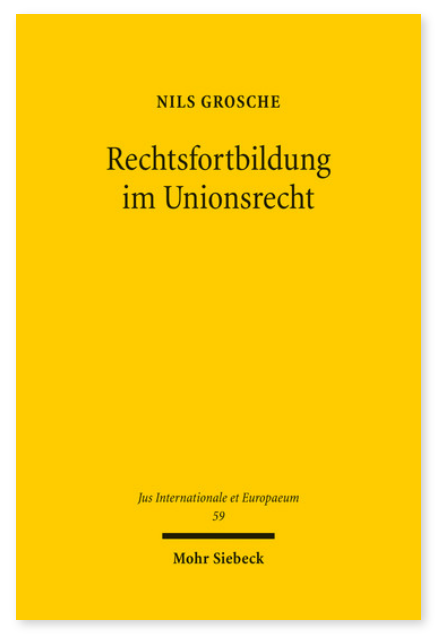

2011. XVII, 351 Seiten. JusIntEu 59

ISBN 978-3-16-151853-9

DOI 10.1628/978-3-16-151853-9

eBook PDF $89,00 €$

ISBN 978-3-16-150992-6

fadengeheftete Broschur $89,00 €$
Wo Richter entscheiden, stellt sich immer die Frage, ob die Entscheidungen dem gesetzten Befugnisrahmen entsprochen haben. Dabei bildet die spezifische Betrachtung des Unionsrechts Anlass für grundlegende Überlegungen zum theoretischen Verständnis von richterlicher Rechtsfortbildung und Spruchpraxis. Nils Grosche deutet richterliche Entscheidungen, einschließlich der als richterliche Rechtsfortbildung rubrizierenden, als Erklärungen der normativen Ordnung, denen darstellender Charakter zukommt. Zur Erklärung der normativen Ordnung bedient sich der Ansatz eines Modells aus Regeln und Prinzipien, das sich an dem Erklärungszusammenhang orientiert. Auf dieser Grundlage untersucht Nils Grosche die Zusammenhänge des Unionsrechts und deren Verknüpfung mit richterlicher Rechtsfortbildung. Für diese Arbeit wurde Nils Grosche mit dem Promotionspreis des Fachbereichs Rechtswissenschaft der Universität Bonn ausgezeichnet.

Nils Grosche Geboren 1982; Studium der Rechtswissenschaften an der Universität Bonn; Referendariat in Köln; 2012 Promotion (Bonn); 2019 Habilitation (Mainz); Lehrstuhlvertretungen in Konstanz und Frankfurt am Main.

Jetzt bestellen:

https://mohrsiebeck.com/buch/rechtsfortbildung-im-unionsrecht-9783161518539?no_cache=1

order@mohrsiebeck.com

Telefon: +49 (0)7071-923-17

Telefax: +49(0)7071-51104 